\section{European space science braces for mission cuts}

Paris. The European Space Agency (ESA) is expected to announce major cuts in its space science programme later this month, including a 10 per cent reduction in the budgets of all its science missions, the cancellation of at least one planned mission and delays to others.

The cuts are part of a drive to reduce costs following last year's decision by ESA's 14 member states to freeze spending on space science over the next three to five years. Also in doubt are plans to collaborate in upgrading the Hubble Space Telescope (see Nature 368, 786; 1994) and to continue operating satellites beyond their scheduled design lifetimes.

This was the gloomy news that emerged from a meeting last month of ESA's Space Science Advisory Committee (SSAC), whose conclusions are expected to be endorsed by its Science Policy Committee at a prognosis meeting next week.

ESA's Horizon 2000 science programme began in 1985 and is scheduled to run until 2005. Four large 'cornerstone' missions, each costing around ECU625 million (US\$795 million) make up the backbone of the programme, which also includes several 'medium-sized' missions at around ECU345 million each. The quality and cost-effectiveness of the programme has been widely acclaimed, and the same structure will be used within Horizon 2000-plus, a series of missions scheduled from 2006 onwards.

The proposed cuts in Horizon 2000 result from the decision taken at last year's ESA space ministers' meeting in Toulouse to freeze annual spending on space science at ECU347 million annually from 1996 to 1998 , when a decision will be taken on whether to extend the freeze until 2000 (sec Nature $377,667 ; 1995)$.

ESA had previously proposed that the budget for Horizon 2000 should be

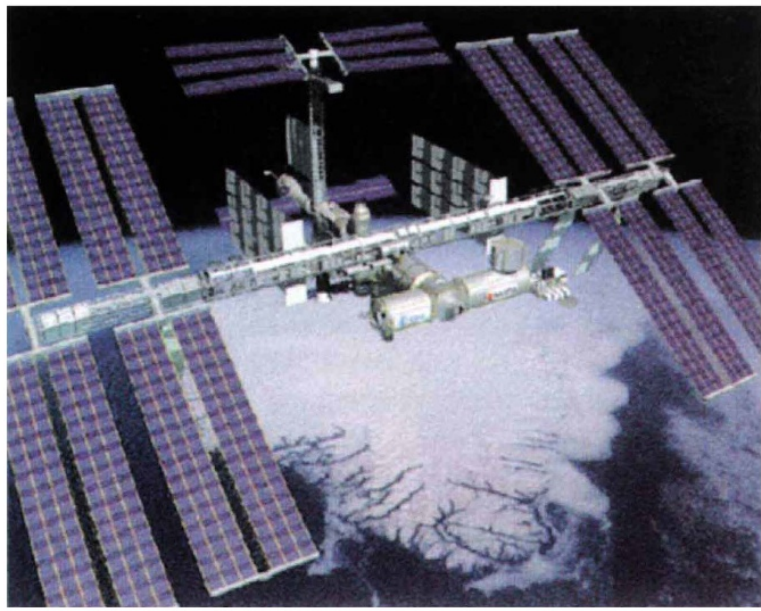

Friend or foe? Space station is putting pressure on budgets, increased at the rate of inflation over the next five years. But this was opposed by both Germany, which argued that the budget should be kept constant, and the United Kingdom, which argued that the agency would be able to cut the costs of its science missions by 25 per cent over this period without reducing their scientific value.

But Roger Bonnet, head of science at ESA, claims the SSAC proposals confirm his prediction that cuts of such magnitude could not be made without jeopardizing the science programme. The proposed 10 per cent cut in all science missions will inevitably increase the risk in the missions, says Bonnet, as they could only be achieved by eliminating parts or using cheaper alternatives. The next medium-sized mission, which is scheduled to be selected in June (see Nature $\mathbf{3 6 9}, 90 ; 1994)$, will be used as a pilot test to decide the possibilities for savings, he says.

\section{Heads roll at French space agency}

Paris. The French government last week announced that it had accepted the resignation of André Lebeau, the president of the French space agency, CNES, and has terminated the contract of JeanDaniel Lévi, the director-general of the agency. Lebeau's successor is Alain Bensoussan, the current president of the national computer technology research agency INRIA; Lévi has not yet been replaced.

Two factors are said to lie behind the reshuffle at the top of CNES. One is the government's reported impatience with a power battle between Lévi, who was appointed in 1990, and Lebeau, who arrived in January 1995, having previously been president of Météo-France. Lévi was also an adviser to the late president François Mitterrand, and his position had been precarious since the election of Jacques Chirac as president .

But some observers feel that an addi- tional reason for the reshuffle is that both Lévi and Lebeau have been lukewarm in their support for the international space station. Their differences with the government are said to have come to a head after it agreed to a large increase in its contribution to the station, at a meeting of Europe's space ministers in Toulouse last October (see Nature 377, 667; 1995).

This decision, reportedly taken under pressure from the German government - Europe's largest supporter of the space station - put paid to Lévi's efforts to stop the escalation of CNES's contributions to the European Space Agency in order to reinforce its national and bilateral programmes. Moreover, in order to help pay for France's space station bill, CNES will have to make economies of 5 per cent a year in its planned budget over the period 1996-2000 (see Nature 378, 5; 1995). Declan Butler
Bonnet also argues that the potential for savings is narrowed by the need to budget for unpredictable events. He points out that the delay to the Ulysses mission, caused by the explosion of the space shuttle Challenger in 1986, cost ESA ECU100 million. Similarly, the costs of the infrared space observatory satellite, which was launched last year, overran because of a two-year delay in the mission caused by technical problems, and an under-estimation of running costs.

But Bonnet's complaints have so far cut little ice with those who continue to believe that ESA can reduce its operating costs considerably without significantly affecting its science programmes. Ian Corbett, for example, director of science at the UK Particle Physics and Astronomy Research Council (PPARC), remains convinced that ESA can restructure its programmes "without any loss of science".

\section{US deal buys into}

Washington. US and Russian space officials steered the international space station project through its latest political storm last week, agreeing on a plan that lets Russia meet its financial commitments to the project while keeping its own Mir station alive for several more years.

The United States will launch two more space shuttle flights to Mir, in addition to the seven that had already been planned. The additional flights, both in 1998 , will carry supplies to the Russian station, which was to have been shut down next year but which will now be extended at least until 1999.

By picking up some of the cost of resupplying Mir, the United States makes it more likely that its cash-strapped partner will be able to pay for the launch vehicles needed to help build the space station. In exchange, the National Aeronautics and Space Administration (NASA) will get more flight time on board Mir for its own astronauts and experiments. 
Corbett says that Bonnet is "facing the challenge positively", pointing out that the proposal to carry out a pilot test is evidence that there is still room for improvement. But he contests Bonnet's claim that the proposed cuts are the direct consequence of the decisions taken at Toulouse, arguing that ESA's proposed mission schedule was already over-ambitious, and that the agency would have had to cancel or delay missions even without the ministerial decision.

Yet while PPARC officials claim that the SSAC proposals are simply a "recognition of this reality", Bonnet says that it is because Horizon 2000 is coming under increasing pressure to deliver more goods than originally planned that further cuts cannot be made without jeopardizing the programme's scientific content.

$\mathrm{He}$ points out that the programme is at the peak of its activities, and that ESA's budget is increasingly stretched by, for example, the need to meet the unanticipated demand of space scientists for the handling and storage of mission data. Similarly, researchers have been keen to exploit the possibilities of continuing to operate satellites, such as Ulysses and Giotto, that have survived beyond their scheduled design lives. But the cuts mean that ESA will probably no longer be able to fund proposals to prolong missions.

Bonnet's protests may seem like crying over spilt milk, given that the decision on the immediate cuts has already been taken. But his vigorous defence of ESA's science programme is based on the prospect of further cuts looming on the horizon. In particular, it is widely expected that Britain - and perhaps other member states - will push for an extension of the budget freeze from 1998 to at least 2000 .

Declan Butler

\section{Italy 'cannot afford' space station role}

Munich. The decision last year of Giorgio Salvini, the Italian research minister, to commit Italy heavily to the European Space Agency's participation in the International Space Station, has been strongly criticized by a panel of prominent scientists. The panel was set up last summer by the Italian government to report on Italy's national and international space programmes.

At the agency's ministerial meeting in Toulouse, France, last October, Salvini ensured Europe's continued involvement in the space station by confirming that Italy would provide 19 per cent of its costs (US $\$ 318$ million) until 2000. But in its report, published in Rome this week, the review panel says that Italy can neither afford such a contribution nor hope to receive significant scientific or industrial returns from the station, which it describes as being empty of any value apart from political prestige.

Members of the group that prepared the report include Antonio Ruberti, Italy's former research minister, Riccardo Giacconi, director of the European Southern Observatory, and Carlo Rubbia, the former head of the European Laboratory for Particle Physics (CERN), who originally advised Salvini not to commit Italy heavily to the programme.

In its report, the group acknowledges that the Toulouse decisions "cannot be ignored". But it proposes that Italy's contributions to the space station should be "reduced to the minimum possible level both during the development phase and on the utilization phase, which is still very poorly defined". It also recommends that Italy "drastically reduces" its agreement with the United States to develop a pressurized logistic module for the space station, which could cost Italy IL535 billion (US\$339 million).

The report was commissioned to analyse the problems that had led to the current financial and administrational chaos in the Italian Space Agency ASI, to recommend ways of rationalizing the agency, and to propose an appropriate space policy for Italy. Its main argument is that a much too high proportion of the agency's budget of around IL1,000 billion a year goes to international space programmes, leaving national programmes underfinanced.

To correct the balance, says the advisory group, Italy's contribution to ESA should be reduced from around IL800 billion this year to around IL430 billion by 2000 by reducing its commitments to optional programmes, such as the space station and Earth observation and telecommunications programmes.

Speaking at a press conference on Monday, 5 February, Salvini hedged the issue of disagreement about participation in the international space station, saying that the agreements he had made at Toulouse were the "inevitable consequences of decisions taken at government level". But he acknowledged there was a need "to reconcile the decisions taken at Toulouse with those proposed in the report". Alison Abbott

\section{Mir to keep Russia on board international station project}

NASA will pick up costs that include $\$ 124$ million for one of the new shuttle flights - the second is being re-programmed from another mission already scheduled - as well as additional costs associated with flying more experiments. Exactly who will pay for what will be worked out at a further meeting in March between Russian and US space officials.

The agreement ends weeks of speculation that the partnership was in danger of falling apart. A proposal from Russia last autumn that the international space station should be built around existing elements of Mir, rather than from scratch, set off alarms both at NASA and in Congress, neither of which want another change of course when the station is due to start construction in November next year.

Daniel Goldin, administrator of NASA, vowed that the station design would not change, and two congressman in charge of NASA funding, James Sensenbrenner (Republican, Wisconsin) and Jerry Lewis
(Republican, California), flew to Moscow last month to emphasize the point.

By that time, however, space station managers at the Johnson Space Center in Houston had already rejected the idea. They also vetoed a Russian proposal, presented at a meeting in Houston in midJanuary, that the United States should pay Russia \$200 million over two years to help meet its obligations. "That [proposal] didn't stay on the table for very long," Wilbur Trafton, head of the space station project, said last week.

In contrast, sending additional shuttle flights to Mir "helps them, and it helps us", says Trafton. The two sides agreed to the plan at a meeting in Washington between US Vice President Al Gore and Russian Prime Minister, Viktor Chernomyrdin.

Although Russian participation in the station seems on a solid footing for the time being, NASA officials admit that future money problems could still jeopardize the partnership. As a hedge, Trafton says engineers at the Marshall Space Flight Center in Alabama are working on contingency plans for building the station if Russia had to pull out.

But another agreement produced by the Gore-Chernomyrdin Commission may make that less likely. The number of commercial Western spacecraft allowed to use Russian launch vehicles is being increased from eight to fifteen. Revenue from those launches, and from experiments flown on Mir for paying customers, should improve Russia's financial position.

NASA, however, will now be looking for ways to pay for one more shuttle mission, as well as additional experiments on Mir, at a time when its budget is already overstretched. The strain is already beginning to show. Last week, Bryan O'Connor, director of the shuttle programme and a former astronaut, left the agency, apparently after disagreeing with a plan to cut NASA's costs by turning the shuttle over to a private operator

Tony Reichhardt 